Educación científica de las niñas, vocaciones científicas e identidades femeninas. Experiencias de estudiantes universitarias

Scientific education of girls, scientific vocations and female identities. Experiences of University students

\author{
Volumen 18, Número 2 \\ Mayo-Agosto \\ pp. 1-31
}

Este número se publica el 1 de mayo de 2018

DOI: https://doi.org/10.15517/aie.v18i2.33136

\author{
Elsa Susana Guevara Ruiseñor \\ María Guadalupe Flores Cruz
}

Revista indizada en REDALYC, SCIELO

Revista distribuida en las bases de datos:

LATINDEX, DOAJ, REDIB, IRESIE, CLASE, DIALNET, SHERPA/ROMEO,

QUALIS-CAPES, MIAR

Revista registrada en los directorios:

ULRICH'S, $\underline{\text { REDIE}}, \underline{\text { RINACE}}, \underline{\text { OEI }}$ MAESTROTECA, PREAL, $\underline{\text { CLACSO }}$ 


\title{
Educación científica de las niñas, vocaciones científicas e identidades femeninas. Experiencias de estudiantes universitarias
}

\author{
Scientific education of girls, scientific vocations and female identities. Experiences of
} University students

\section{Elsa Susana Guevara Ruiseñor ${ }^{1}$ María Guadalupe Flores Cruz ${ }^{2}$}

\begin{abstract}
Resumen: En México, como en toda América Latina, la educación científica de sus jóvenes constituye una imperiosa necesidad económica y social, especialmente en el caso de la población femenina que se encuentra subrepresentada en sus sistemas de ciencia y tecnología. Los estudios sobre género y ciencia han aportado suficiente evidencia sobre los obstáculos que representan los ordenamientos de género para la construcción de vocaciones científicas en las niñas y jóvenes, así como la importancia de la escuela y la familia para reproducir o transformar esos patrones. Esta investigación se propuso como objetivo conocer la forma como operaron los ordenamientos de género en la educación científica recibida durante la infancia en estudiantes universitarias y su impacto en la construcción de vocaciones científicas y su interés por la investigación. Para ello se utilizó como estrategia metodológica la entrevista cualitativa en profundidad, mediante entrevistas aplicadas a ocho alumnas de las carreras de Psicología y Biología de la UNAM. Los resultados mostraron que las estudiantes de Biología vivieron una socialización de género menos tradicional en la familia y en la escuela, y una educación científica durante la infancia que contribuyó a promover vocaciones científicas en ellas, incentivar interés por estudiar una carrera universitaria y dedicarse a la investigación. Tales hallazgos permiten identificar el importante papel que cumple la socialización de género no tradicional para facilitar la educación científica de las niñas y jóvenes, pero también del importante papel que ésta cumple para romper con los modelos femeninos tradicionales y optar por una carrera científica.
\end{abstract}

Palabras clave: educación, ciencia, género, estudiantes universitarias

Abstract: In Mexico, as in Latin America, the scientific education of its young constitutes an economic and social imperative especially for the female population that is underrepresented in their science and technology systems. Studies on gender and science have provided enough evidence about the obstacles that represent gender systems to promote the scientific vocations in girls and young women, as well as the importance of the school and the family for reproduce or transform these patterns. This research was proposed as a goal know the way in which operated on the systems of gender in the scientific education of women students during her childhood, its impact on the construction of scientific vocations and her interest in research. We used as a methodological strategy the qualitative interview to depth, these interviews were applied to eight women students for psychology and biology of the UNAM. The results showed that the biology students lived a socialization of less traditional gender in the family and at school, and a scientific education in childhood that contributed to create scientific vocations in them, to promote her interest by university career and devote herself to the research. Such findings identify the important role that complies non-traditional gender socialization to facilitate the scientific education of girls and young women, but also the importance of scientific education of girls for to break traditional female models and choose the scientific career.

Key words: education, science, gender, university students

\footnotetext{
1 Profesora Titular en la Carrera de Psicología de la FES "Zaragoza" Universidad Nacional Autónoma de México. Investigadora Nacional Nivel Il e integrante de la Red Mexicana de Ciencia, Tecnología y Género. Doctora en Sociología. Dirección electrónica: elsaruisenor@hotmail.com

2 Profesora en la Facultad de Psicología de la Universidad Nacional Autónoma de México y de la Universidad Latina de la Ciudad de México. Doctora en Neurociencias y Licenciada en Psicología por la UNAM. Dirección electrónica mgfcruz@gmail.com
}

Artículo recibido: 8 de noviembre, 2017

Enviado a corrección: 28 de febrero, 2018

Aprobado: 9 de abril, 2018 


\section{Introducción}

La educación científica de las jóvenes y las niñas adquiere cada vez mayor relevancia en el ámbito internacional sobre educación y ciencia porque se ha podido comprobar que su exclusión representa un problema de justicia social que es necesario atender, pero también por los beneficios que ello trae a la sociedad en su conjunto. Esta educación permite a las niñas prepararse para una participación más efectiva en la solución de los grandes problemas que les tocará vivir, incentivar sus vocaciones científicas y motivarlas a estudiar carreras del área de la ciencia y la tecnología donde las mujeres están subrepresentadas. Sin embargo, su educación científica enfrenta serias dificultades, especialmente en regiones como las de América Latina y el Caribe, pues como señalan Céspedes y Robles (2016), ellas se desarrollan en circunstancias particulares por el entrecruzamiento de dos factores que se potencian: el ser mujeres y menores de edad, además de que muchas de estas niñas enfrentan obstáculos por su condición étnica y de clase, lo que suele traducirse en diversas experiencias de discriminación o sexismo. Los informes de la Unión Europea (ENWISE, 2004; ETAN, 2000) y más recientemente, en la Cátedra Regional UNESCO 2014 (Bonder, 2014), señalan la necesidad de crear medidas que atiendan la desigualdad que viven las mujeres en el campo de la ciencia, puesto que incorporar a las niñas y jóvenes al campo científico representa beneficios tanto para el desarrollo de los países como para la ciencia misma; todas las mujeres que no pueden progresar en la carrera científica representan una pérdida para cada país, dado el desperdicio de talento y recursos humanos que no fueron aprovechados. Por ello, proponen que universidades e instituciones científicas tomen medidas y acciones concretas para solucionar esta situación.

Ya en la Cumbre de la Tierra organizada por la ONU en Rio de Janeiro, Brasil en 1992, se subrayaba la necesidad de incluir a las mujeres en los debates sobre el medio ambiente, pues no era posible hacer un uso racional de la tierra, del manejo adecuado del agua, la protección de los bosques o la preservación de la biodiversidad si no se consideraba que las mujeres tenían un papel central en cada uno de estos ámbitos, y para ello, era necesario poner atención a su educación científica, pues si no tenían suficiente escolaridad e información para comprender los riesgos y adaptar su conducta a nuevas situaciones, era muy difícil resolver los ingentes problemas que enfrenta el medio ambiente. Sin embargo, de acuerdo con la Organización para la Cooperación y el Desarrollo Económicos OCDE (2015), menos de 1 de cada 20 niñas considera estudiar una titulación en ciencia, tecnología, ingeniería o matemáticas, mientras que 1 de cada 5 niños se inclina por esta opción; es de 
suponer que la brecha de género en edad temprana tendrá un impacto en la elección de los estudios científicos y las oportunidades para desarrollarse en esta área.

Como señala Nuño (2000, p. 192), durante mucho tiempo se atribuyó la causa de la escasa presencia de las mujeres en la ciencia a su desinterés personal en estas áreas, o bien, a supuestas carencias innatas que limitaban sus posibilidades de inclinarse por estas carreras universitarias, de manera que se consideró necesario tomar medidas para compensar esas "deficiencias". Hoy diversas investigaciones han podido mostrar que el problema no radica precisamente en las mujeres, sino que es resultado de una socialización diferencial por género inherente a la ciencia misma, a la forma de enseñarla y a las expectativas familiares y sociales que limitan las oportunidades de las niñas y mujeres para desarrollarse en el campo de la ciencia.

\section{Referentes teóricos}

Desde la década de los 60' cuando se publicó el artículo pionero Women in Science: ¿Why so few? (Rossi, 1965), se abrió un debate en el tema de género y ciencia para preguntarse sobre las razones por las cuales las mujeres estaban, y lo siguen estando, subrepresentadas en los sistemas de ciencia y tecnología. Desde entonces se han desarrollado múltiples estudios que muestran la paradoja, todavía vigente, de que pese al incremento consistente de las mujeres en las universidades su presencia en el área de ciencia y tecnología sigue siendo minoritaria. Todo ello como resultado de la forma en que operan los regímenes de género ${ }^{3}$ en las instituciones educativas y científicas que limitan las oportunidades de las mujeres para dedicarse a la investigación y la ciencia. Entre ellas destacan: las creencias de que los varones están mejor dotados para las disciplinas científicas; la utilización de estereotipos sexistas en la escuela; criterios de evaluación que descalifican las habilidades de las mujeres; las menores expectativas académicas que deposita el profesorado, y a veces la familia, en las chicas; así como practicas pedagógicas que tienen como modelo la forma de pensar y el mundo intelectual de los varones. Es decir, se ha podido mostrar que la enseñanza-aprendizaje de la ciencia no se dirige a un sujeto neutro, ni lo hace con contenidos y metodología equilibrados sino que se utilizan diferentes

\footnotetext{
${ }^{3}$ El género es una categoría que surge a partir del principio de que lo femenino y lo masculino no son hechos naturales o biológicos, sino construcciones culturales que traducen la diferencia sexual en desigualdad social y política. Esta categoría permite comprender el modo esencial en que la realidad social se organiza, se divide simbólicamente y se vive empíricamente como un campo de relaciones asimétricas de poder que coloca a las mujeres en posiciones subalternas en la sociedad (Cobo, 1995, p. 55).
} 
estrategias que, en la práctica, van marginando a las alumnas de las opciones científicas y técnicas (Clair, 1995; González y Pérez, 2002; Graña, 2006; Harding, 1996; Keller, 1995).

Se tiene evidencia de que padres y madres tienen mayores expectativas de que sus hijos varones estudien carreras de ciencia, tecnología, ingenierías y matemáticas, aun cuando sus hijas muestren las mismas capacidades que sus cohortes masculinos. Lo mismo ocurre con el cuerpo docente, quienes suelen dar un trato privilegiado a los niños, sostienen mayores expectativas de que sus alumnos varones tendrán un mejor desempeño en ciencias que las niñas y es frecuente que desplieguen prácticas pedagógicas que excluyen, invisibilizan o discriminan a las niñas. (García Ramírez, 2014; Guevara, 2012; Mingo, 2006; Riquelme y Quintero, 2015).

En México se ha prestado poca atención al tema ${ }^{4}$, pese a que existen datos preocupantes al respecto. La Encuesta sobre la Percepción Pública de la Ciencia y la Tecnología en México (INEGI, 2013) muestra que 75\% de las mujeres entre 18-29 años manifiesta su desinterés en los temas de ciencia y tecnología, ellas exponen como razones que no los entiende o no le interesan, contra $67.8 \%$ de los varones que dieron las mismas respuestas. En el examen PISA (OCDE, 2015) donde el estudiantado mexicano obtuvo los puntajes más bajos de todos los países de la OCDE en matemáticas, se señala que los hombres obtuvieron, en promedio, puntajes más altos que las mujeres, y que éstos alcanzan hasta 16 puntos de diferencia entre estudiantes de alto desempeño. Ante esta situación, la comunidad científica se ha encargado de promover diversas acciones de divulgación y educación científica entre la población infantil y adolescente, sin embargo, rara vez consideran el papel que cumplen los ordenamientos de género en estos procesos ${ }^{5}$. Se asume que estas acciones serán suficientes en sí mismas para estimular el interés de niñas y niños por carreras científicas, pero la investigación educativa sobre género y ciencia muestra que no es así, puesto que en la escuela y en la enseñanza de la ciencia se reproducen desigualdades de género que colocan en desventaja a las chicas mediante sus programas formales, sus prácticas pedagógicas y un currículo oculto que orienta

\footnotetext{
4 En términos formales se supone que la educación científica forma parte de los programas de estudio que imparten en todas las instituciones educativas del país, sin embargo, se sabe que las ciencias han ocupado un lugar secundario en la educación básica y que las estrategias de enseñanza de la ciencia son muy deficientes en general, pero estas deficiencias se agudizan en determinados sectores según la región, clase social, etnia y sexo de la población (Flores-Camacho, 2012, p. 5).

5 Pese a que se ha vuelto políticamente correcto hablar de la perspectiva de género, todavía como dice Diana Maffía (2005, p. 623), no se ha reconocido estatus epistémico a esta perspectiva y se considera más como una ideología o como una crítica social que como un nuevo paradigma en la construcción del conocimiento, por tanto, se le deja fuera del debate científico para analizar los temas educativos.
} 
expectativas, aspiraciones y comportamientos diferenciales en unas y otros (Aguiar, Gutiérrez, Lara y Villalpando, 2011; Álvarez-Lires, Arias, Serrallé y Varela, 2014; Espinosa, 2009; Guevara, et al, 2016).

Tampoco los estudios sobre vocaciones científicas han concedido importancia a los ordenamientos de género que imperan en la escuela, la familia y la sociedad para limitar la educación científica ${ }^{6}$ de las niñas y su interés por la ciencia, pese a la abundante bibliografía que señala los distintos obstáculos que se impone a las niñas y jóvenes para su aprendizaje de la ciencia (Manassero y Vázquez, 2003). Como han apuntado León y Mora (2010, p. 407) tanto mujeres como varones llegan a tener o no vocación científica en función de las experiencias por las que pasan en sus primeros contactos con el mundo de la ciencia. Dado que existe una desigualdad estructural entre mujeres y varones, las actividades en las que unas y otros obtienen satisfacción y evidencia de su propia valía son distintas, de modo que se produce una diferencia de género en el tipo de "Ilamada" vocacional que "recibe" cada uno/a. También se ha podido observar que la socialización de género en la infancia, tanto en la escuela como en la familia, tiene importantes consecuencias para estimular o limitar las capacidades asociadas a la ciencia entre las niñas y los niños, pues mientras a las niñas se les socializa con juegos y juguetes asociados al mundo de los afectos, lo doméstico y el cuidado; a los niños se les socializa en la acción, los retos intelectuales y la competencia; actividades que les permite desarrollar habilidades e intereses que se encuentran más vinculados a las actividades científicas (Duru-Bellat, 1995; Moreno, 1993).

Esta socialización también tiende a reforzar los estereotipos de género y orientar gustos, preferencias, comportamientos diferentes entre las niñas y los niños que, con frecuencia, tienden a desalentar a las niñas de acercarse al terreno de la ciencia. Se ha visto que a los 12 o 13 años las niñas ya tienen estereotipos formados de lo que les gusta o no y de lo que sería más conveniente para sus estudios, y resulta que para ese momento, muchas de ellas ya han excluido la ciencia de su área de interés (Carrera, Subirats y Tomé, 2014). Sin embargo, también existe una porción importante de mujeres jóvenes que manifiestan su inclinación por estudiar carreras científicas y dedicarse a la ciencia; a veces

\footnotetext{
6 La educación científica tiene como objetivo lograr una educación en ciencia que permita a las personas reconocer no sólo los principales conceptos, hipótesis y teorías de la ciencia, sino usarlos en la resolución de problemas, la comprensión del mundo y la toma de decisiones. Así, el aprendizaje de la ciencia debe garantizar que las personas se apropien de redes de significados científicos más allá de las palabras por sí mismas, que reflexionen sobre ellos y sean capaces de utilizarlos en contextos específicos (Sañudo y Perales, 2014, p. 30).
} 
incluso en mayor proporción que sus compañeros varones ${ }^{7}$, lo que indica que algunas chicas logran superar los diversos obstáculos asociados a su condición de género y que la educación científica recibida en algún momento de su trayectoria escolar puede haber incidido en esta situación.

Ante este panorama, nos interesó conocer la forma en que operaron los ordenamientos de género en la educación científica recibida durante la infancia en estudiantes universitarias y cuál fue su impacto en la construcción de vocaciones científicas y en su interés por la investigación. Es decir, se trató de conocer: ¿Cómo opera la socialización de género en la escuela y la familia para facilitar u obstaculizar la educación científica que recibieron durante la infancia estudiantes universitarias? ¿Qué papel cumple esta educación en la construcción de vocaciones científicas en las mujeres? ¿Cómo interviene para que ellas puedan superar con éxito los distintos obstáculos en su trayectoria escolar derivados de su condición de género? ¿Cuál es su papel en la construcción de identidades femeninas?

\section{Metodología}

Con el propósito de responder tales interrogantes, se realizaron entrevistas cualitativas a profundidad a ocho estudiantes universitarias que cursaban los últimos semestres de las carreras de Psicología y Biología en la Facultad de Estudios Superiores-Zaragoza de la Universidad Nacional Autónoma de México. El único criterio de selección fue que se encontraran cursando los últimos semestres en alguna de esas carreras y que aceptaran participar en la investigación. En las entrevistas se exploraron sus experiencias de educación científica desde la infancia hasta su ingreso a la universidad, tanto en la familia como en la escuela; la socialización de género que vivieron en estas instituciones mediante los juguetes y juegos que practicaron; el futuro profesional que avizoraron desde niñas; y sus perspectivas respecto a dedicarse o no a la investigación científica ya en esta etapa de su vida adulta. Se eligieron estas carreras porque en ambas las mujeres son mayoría en la matrícula estudiantil (69\% de mujeres en psicología y $57 \%$ en Biología), y por eso mismo, son consideradas carreras "femeninas", sin embargo, cada una ocupa un lugar distinto en la jerarquía de las ciencias, pues mientras la Biología es percibida como una disciplina científica en toda la extensión, la psicología es vista más como una profesión que como una

\footnotetext{
7 En un estudio con estudiantes de 14 carreras de la UNAM, el 57.8\% de las mujeres manifestaron su intención de dedicarse a la investigación, contra $49.7 \%$ de los varones y únicamente en las carreras de ciencias ambientales y física, fue inferior el porcentaje de mujeres que afirmaron su propósito de dedicarse a la investigación (Guevara, 2012, p. 34).
} 
ciencia. Las entrevistas fueron realizadas en las instalaciones de la universidad, respondidas de manera voluntaria y anónima por las participantes y grabadas con su consentimiento8.

Se optó por la entrevista cualitativa a profundidad $^{9}$, porque esta herramienta metodológica permite tener una perspectiva integral de cómo se articulan los factores sociales y personales en la educación científica de las estudiantes a lo largo de su trayectoria escolar. Se trata, como señala Bourdieu (1993), de acercarse a la comprensión de los modos de actuar en el mundo y representarlo de acuerdo a las propias condiciones de las personas participantes. Taylor y Bogdan (1987) a su vez, afirman que estos encuentros cara a cara entre la persona que investiga y quienes participan como informantes, permite comprender las perspectivas que tienen las personas respecto de sus vidas, experiencias 0 situaciones, tal como las expresan con sus propias palabras. Es también, como señala Vela (2001, p. 63), una estrategia adecuada para el análisis de la subjetividad y el significado de la acción social.

\section{Resultados y su análisis}

\subsection{El perfil de las estudiantes entrevistadas}

Todas las estudiantes entrevistadas cursaban sus estudios en una Facultad multidisciplinaria situada en los márgenes de la Ciudad de México, eran solteras y contaban entre 20 y 23 años; no tenían hijos/as y vivían con su familia de origen. Las cuatro estudiantes de biología y una de psicología no profesan ninguna religión, mientras que tres estudiantes de psicología se declaran católicas. Todas las jóvenes manifiestan haber tenido un excelente desempeño académico durante su educación primaria y seis de ellas cuentan con al menos un progenitor que cursó estudios universitarios. En la tabla 1 se pueden observar algunas características de las estudiantes entrevistadas.

\footnotetext{
${ }^{8}$ Si bien no se solicitó un consentimiento informado por escrito, sí se les informó sobre los objetivos del estudio, su carácter confidencial y anónimo, así como su derecho a proporcionar sólo la información que ellas consideraran pertinente. Se les solicitó su autorización para grabar en audio la entrevista y para divulgar algunas de sus narraciones en medios de divulgación científica como artículos, ponencias o conferencias donde se presentaran los resultados de la investigación. También se les proporcionó información sobre la ubicación de la académica responsable del proyecto y su disposición para atenderles sobre cualquier duda respecto a la investigación.

${ }^{9}$ Como señala Roberto Castro (1996): "A diferencia de los métodos cuantitativos que se concentran en el estudio "objetivo" de fenómenos externos a los individuos, los métodos cualitativos privilegian el estudio "interpretativo" de la subjetividad de los individuos, y de los productos que resultan de su interacción. El aspecto sociológico central de esta perspectiva se refiere al significado que la realidad tiene para los individuos y la manera de que estos significados se vinculan con sus conductas" (p. 64). Por tanto, la investigación cualitativa no utiliza recursos metodológicos como: sujetos, variables o muestras, No busca representatividad, puesto que no pretende generalizar sus resultados sino profundizar en la comprensión del fenómeno de estudio.
} 
Tabla 1. Perfil de las estudiantes entrevistadas

\begin{tabular}{c|c|c|c|c|c|c}
\hline Nombre $^{10}$ & Carrera & Edad & Religión & Esc. Padre & Esc. Madre & $\begin{array}{c}\text { Enseñanza } \\
\text { ciencia } \\
\text { Primaria }\end{array}$ \\
\hline Magda & Biología & 23 & Ninguna & Licenciatura & Licenciatura & Tradicional \\
\hline Raquel & Biología & 23 & Ninguna & Licenciatura & Licenciatura & Activo \\
\hline Flor & Biología & 23 & Ninguna & Lic. trunca & C. Técnica & Activo \\
\hline Violeta & Biología & 20 & Ninguna & Licenciatura & Licenciatura & Activo \\
\hline Delia & Psicología & 21 & católica & Lic. trunca & C. Técnica & Tradicional \\
\hline Lila & Psicología & 21 & católica & Secundaria & Secundaria & Tradicional \\
\hline Silvia & Psicología & 21 & No tiene & Secundaria & Primaria & Tradicional \\
\hline Ruth & Psicología & 21 & católica & Licenciatura & Licenciatura & Tradicional \\
\hline
\end{tabular}

Fuente: Elaboración propia (2017) con los datos proporcionados por las estudiantes entrevistadas

\subsection{Su educación científica en la infancia y la socialización de género}

Salvo una de las estudiantes de Biología, las otras tres entrevistadas presentan ciertas similitudes en sus historias respecto a la educación científica recibida en su infancia y su socialización de género. Flor y Violeta cursaron su educación preescolar y primaria en escuelas que tenían sistemas activos de enseñanza de la ciencia y mencionan haber vivido una infancia donde la ciencia formaba parte de su universo cotidiano, de manera que tanto su familia como la escuela jugaron un papel importante para promover su interés y entusiasmo por la ciencia; esto les permitió acercarse al conocimiento científico de una manera divertida, descubrir un mundo apasionante y desarrollar habilidades científicas. Raquel recibió su educación científica principalmente de su familia porque cursó su educación primaria en una escuela de monjas donde no recibía educación científica, pero sus progenitores sí reconocían la importancia de este tipo de educación y se encargaron de acercarla al conocimiento científico y promover una socialización de género que incluía diversas actividades relacionadas con la ciencia: le compraban juguetes científicos, compartían con ella documentales de ciencia y le regalaban libros de astronomía, todo ello hizo que disfrutara del conocimiento científico desde pequeña. Así relata su experiencia:

Yo iba a una escuela de monjas, y eso de la ciencia sí nos lo enseñaban pero no le daban como que mucha importancia. Como mis padres decían que era importante darle a un niño en qué creer, entonces decidieron que la primaria la hiciera en una escuela católica, pero al mismo tiempo me enseñaban lo que era la ciencia, me daban pues mis juegos científicos, me ponían mis documentales, me compraban mis libros de astronomía. Yo tenía el microscopio de Mi Alegría, y era feliz con mi microscopio, me

\footnotetext{
10 Se utilizan nombres ficticios para proteger el anonimato de las estudiantes entrevistadas.
} 
encantaba, yo me desesperaba porque nunca veía las células, y es que a mí siempre me han gustado mucho los documentales de National Geographic, de naturaleza, de animales; también veía los relacionados a desastres naturales, pero siempre terminaba llorando porque yo decía ¿cómo era posible que le hicieran eso a los animalitos?

Raquel

Flor por su parte, señala la importancia que tuvo en su infancia una buena educación científica en la escuela que le permitía disfrutar de las ciencias naturales y las matemáticas, así como una socialización de género no tradicional en su familia donde tenía opción a distintos tipos de juguetes que iban desde muñecas y patines hasta juguetes científicos. En especial ella recuerda cuando le regalaron su primer microscopio.

De niña todavía no tenía el concepto de ciencia pero me llamaba la atención las ciencias naturales, también me gustaban las matemáticas y era muy buena en esa materia (...) En la escuela hacían ferias de ciencia donde te pedían hacer algún experimento y había un jurado que seleccionaba a los mejores y me acuerdo que yo hice el típico volcán y en sexto una alarma sísmica.(...) de juguetes yo tenía los clásicos, muñecas y esas cosas, pero también me gustaban los juguetes que se consideraban para niños: bicicletas, patines...lo que creo que me marcó es que cuando estaba en sexto de día de reyes recibí un microscopio Mi-Alegría y todo lo quería ver en el microscopio: hojas, cabello, fibras. Obviamente no tiene la potencia de uno profesional pero es mejor que la lupa.

Flor

Violeta refiere haber recibido una educación científica en la escuela primaria que le resultaba interesante, lúdica y divertida. Señala que su escuela contaba con un sistema pedagógico donde las y los infantes podían acercarse a la ciencia sin los cartabones formales y vivirla como parte de sus juegos; como un proceso que se construye en grupo y no de manera individual; esas experiencias despertaron en ella una gran pasión por el conocimiento científico y le proporcionó una sólida formación académica. Si bien ese ambiente desaparece cuando ella egresa de esa escuela, la educación científica adquirida y la socialización de género no tradicional la dotaron de mejores herramientas para enfrentar los desafíos de su condición de género en los ciclos escolares siguientes. 
En la escuela había una mesa con muchos juegos y en los juegos te enseñaban matemáticas, entonces yo era muy buena en matemáticas, yo salí del Kinder y yo ya sabía multiplicar, entré a la primaria y yo ya sabía todo lo de cuestiones de algebra porque yo solita las hacía. Incluso, teníamos un horario o bueno, no un horario, tu escogías a qué hora querías estar en una materia, entonces ibas a la mesa y tenías como un cierto tiempo para estar ahí, siempre tenía problemas con las maestras porque yo siempre me la pasaba en la mesa de ciencias y en la de matemáticas, nunca me iba a la de artes, literatura o español, entonces como que agotaba mis horas en ciencias y matemáticas. Pero cuando me pasaron a la secundaria de gobierno [todo cambió] fue como de -ay no ¿qué es esto? entonces yo me confundí, y ya de ahí me costaron mucho trabajo las matemáticas. Todo era individual y eso me enojaba mucho y les peleaba a los maestros que estaban mal [¿Y qué te decían los maestros?] Me sacaban del salón [risas].

Violeta

En cambio Magda afirma no haber recibido ese tipo de educación en la escuela ni en su familia, aunque tuvo un acercamiento incipiente a la ciencia con asistencias a museos y acceso a juguetes científicos de química o microscopios infantiles, su área de interés estaba más orientada al arte que a la ciencia. Este es su relato:

De chiquita me gustaba cantar y dibujaba mucho, ya más grande jugaba a baloncesto y una vez tuve un microscopio y un juego de química. En la primaria siempre tuve buenas calificaciones, todos los años estuve en el cuadro de honor... pero yo no recuerdo haber tenido ferias de ciencia ni nada de eso. Era una escuela pública y era aburrida. En mi casa sí íbamos a museos, a veces.

Magda

Las estudiantes de psicología muestran un panorama algo diferente de la educación científica recibida en su infancia. Ellas cursaron su educación primaria en escuelas con sistemas tradicionales de enseñanza y refieren un ambiente escolar y familiar donde la ciencia no estaba presente como una actividad importante, sin embargo, eran niñas con un buen rendimiento académico. Señalan una ausencia de educación científica en su formación escolar porque las clases se impartían de manera rutinaria y no lograban despertar su interés y menos vivirla como una actividad divertida o interesante. En la familia tampoco contaron 
con un ambiente que estimulara su interés científico y les permitiera involucrarse personalmente con este tipo de actividades, además de que vivieron una socialización de género más tradicional donde las actividades de las niñas estaban más relacionadas a lo doméstico.

Delia, por ejemplo, señala haber vivido un ambiente escolar y familiar donde la ciencia estaba prácticamente ausente y su socialización de género se vinculaba con juegos y juguetes "propios para niñas". Aunque ocasionalmente recibió algunos juguetes asociados a ciertos roles profesionales y accedió a programas televisivos de divulgación científica, la ciencia no formaba parte de su mundo de intereses.

No, nunca asistí a ferias de ciencia, en la escuela veíamos lo que teníamos que ver y ya... con mis papás tampoco platicábamos de ciencia... no, no tenía libros de ciencia... yo jugaba con muñecas, trastecitos, bicicletas y cosas de niñas porque como éramos puras mujeres...lo que sí es que veía los programas de Beak-man y mis papás me regalaron alguna vez juguetitos de doctora o de dentista.

Delia

En el caso de Lila es más evidente esta ausencia de educación científica en la escuela y en la familia. Ella fue una niña con buen desempeño escolar, pero el conocimiento adquirido no tenía para ella relación alguna con el mundo científico, ni contó con actividades escolares que promovieran su interés por la ciencia. Además, refiere un ambiente familiar donde prevalecían los estereotipos de género y se privilegiaban los roles femeninos tradicionales, en especial por parte de su madre, quien la conminaba a ver telenovelas mientras desalentaba su interés por los programas de divulgación científica.

En el Kinder yo ya tenía clases de escritura, de lectura, salí leyendo y escribiendo, sumando y restando, así que en la primaria era buena estudiante, pero de ciencia no, no veíamos algo así específico, ¿profesores? tampoco, ni ferias de ciencia en la escuela (...) Yo jugaba a las Barbies y a la cocinita nada más... el único programa de ciencia que veía de vez en cuando era el de Beak-man, pero más bien veía las telenovelas que había para niños, porque a mi mamá le gustaba más, ella prefería que viera telenovelas a que viera esos programas [de ciencia].

Lila

Silvia muestra el mismo panorama: buen desempeño escolar y ausencia de educación científica en la familia o la escuela, pero una identidad femenina en ciernes que tendía a 
resistir los modelos femeninos tradicionales. Si bien ella no vivió abiertamente condiciones que desalentaran su interés por la ciencia, sí vivió una socialización de género donde eran evidentes las presiones para obstruir las dimensiones más dinámicas de su personalidad y ajustarla a un rol femenino de obediencia y pasividad. Éstas aparecían como influencias sutiles en los juguetes que debía pedir, en los juegos que la alentaban a jugar y en las descalificaciones que recibía al intentar actividades que no eran consideradas "propias para niñas". Estas condiciones coartaban su iniciativa y creatividad, al tiempo que restringían sus posibilidades de desarrollar destrezas o habilidades que suelen ser consideradas del mundo masculino.

Algunos maestros nos pedían que viéramos el mundo de Beak-man y repetir el experimento y eso estuvo muy chido, pero nada más (...) mi hermana como que tenía mucha influencia en mi por ser la menor y me decía 'pide juegos de mesa', y yo por ejemplo quería un juego de química Mi Alegría o cosas así raras, y ella 'ay no pide este juego de mesa o nenucos', y yo, bueno, también tenía muñecas, pero me gustaban las pelotas, cuerdas, todo eso (...) Siempre fui como muy inquieta, muy latosilla y siempre he sido muy niño, entonces por ejemplo, yo les decía vamos a jugar a los quemados o vamos a jugar futbol, pero las profesoras [decían] ay no, eso es juego de niños y las mismas niñas ya hasta me empezaban a decir machorra.

Silvia

Ruth menciona un ambiente familiar rico en recursos literarios, pero alejado de la ciencia, así como un sistema escolar donde tampoco figuraban actividades científicas. Sus juegos y juguetes eran los tradicionales de niña y no tuvo acceso a aquellos de carácter científico debido a la falta de recursos económicos. Con todo, refiere que cuando estaba más grande sí disfrutaba de programas de divulgación científica.

Jugaba con muñecas Barbie y esas cosas, una vez le pedí a mi padre un microscopio, pero mmm estaba muy caro y entonces no, desertamos (...) En mi casa había muchos libros, pero eran más bien los clásicos, caperucita y de esos, pero de ciencia, mmm casi no... en el Kinder ni en la primaria tampoco, ahí hacían más bien kermeses pero nunca ferias de ciencia... Lo que sí es que me encantaba ver a Beak-man y Bizbirije, ahí pasaban algunos experimentos... ya más grande veía de vez en cuando programas de History Channel y National Geographic.

Ruth 
En todas las estudiantes entrevistadas resulta evidente que la educación científica y la socialización de género que recibieron durante su infancia fue gestando en ellas gustos y preferencias vocacionales que las llevaron avizorar la posibilidad de estudiar una determinada carrera universitaria. Es decir, la educación científica o la ausencia de este tipo de educación, estaba vinculada a cierta socialización de género que tuvo un impacto en las expectativas de futuro profesional que se plantearon desde niñas. Para algunas, su acercamiento al mundo de la ciencia les permitió descubrir un mundo apasionante de conocimiento y posicionarse como niñas dentro de él. Otras debieron construir una identidad donde lo femenino, y ellas mismas, estaban situadas al margen de esos territorios. La escuela y la familia como instituciones normativas y generadoras de identidades se encargaron de promover una socialización de género que orientó de alguna manera sus vocaciones profesionales ${ }^{11}$ hacia lo modelos femeninos propios de su cultura, y en este proceso, tuvo un papel muy importante esos primeros acercamientos a la ciencia que, también orientaron sus intereses hacia la carrera que habrían de elegir más tarde. Ellas debieron conciliar estos modelos femeninos con sus vocaciones científicas, lo que ocurre en medio de resistencias y contradicciones que se agudizan durante la adolescencia cuando la familia deja de tener cada vez menos influencia en sus proyectos profesionales y aumenta la importancia de la escuela y de sus grupos de pares para definir su futuro. Todas superaron satisfactoriamente los retos académicos del nivel medio e ingresaron a la universidad en la carrera que actualmente estudian.

\subsection{La construcción de vocaciones científicas: el futuro profesional que avizoraron de niñas}

En los relatos de las jóvenes universitarias es posible apreciar que el ambiente intelectual en el que se desarrollan durante su infancia les proporcionó importantes referentes para vincular sus intereses y preferencias personales con sus aspiraciones profesionales, y éstas se constituyen en el punto de partida en la construcción de sus vocaciones científicas. Las aspiraciones profesionales en la infancia están presentes en las

\footnotetext{
11 Resulta interesante descubrir que en los varones también se ha podido observar este vínculo entre socialización de género y carrera profesional. En una investigación con historias de vida de estudiantes de la UNAM, el estudiante de ingeniería narra una infancia donde predominaban juegos y actividades como: futbol, básquetbol, karate, water-polo y fútbol americano, actividades que se practicaban sólo entre varones; mientras que el estudiante de Artes Visuales relata una infancia donde las niñas participaban en su equipo de futbol y en sus diferentes juegos, en tanto que él jugaba a la casita, a los pasteles de lodo y a la comidita con ellas (Guevara, 2010, p. 180).
} 
cuatro estudiantes de Biología: Magda y Violeta pensaban estudiar biología o áreas afines, mientras que Raquel y Flor pensaron primero en otra carrera, y más tarde, optaron por la biología; pero todas coinciden en haber tenido aspiraciones universitarias desde pequeñas. Estas aspiraciones se van modificando a lo largo de su trayectoria escolar, y será en el bachillerato cuando finalmente se decanten por una carrera que tiene como objeto de estudio la vida en sus diversas manifestaciones. Estos son sus relatos:

Yo decía que quería ser veterinaria o bióloga... pero era porque mi mejor amiga de la primaria decía -yo quiero ser bióloga marina- ¿bióloga marina? ¿qué es eso? (risas) y yo decía lo mismo, también quiero ser eso, pero yo no sabía que era. De hecho, a mí me gustaban mucho los animales y decía que quería ser veterinaria (...) Pero en la secundaria me desmotive, yo decía - no quiero nada de química, ni biología- sentía que yo no servía para eso. Fue hasta la prepa que nos mandaban a conferencias o museos como Universum y nos mandaban a exposiciones, y entonces me gustó y me decidí por la biología.

Magda

De niña quería ser psicóloga, pero mi inclinación siempre fue a la biología, porque siempre me ha gustado ver a los animales, las plantitas, los insectos... me gustan las clases de física, pero ya en práctica me gusta más la biología. Fue en el CCH Sur, cuando me empezó a gustar más, yo creo que me tocó mucha suerte por los maestros que me tocaron, y aparte que siempre me ha gustado la naturaleza y el ambiente y me tocaron maestros que realmente sí hacían prácticas de laboratorio, y me gustó estar en el laboratorio, y dije pues biología es lo que quiero.

Raquel

Yo estaba [por elegir] entre física y biología, porque en el $\mathrm{CCH}$ tenía un maestro de física que era muy gracioso, tenía esa chispa para impartir clase y sus clases eran muy didácticas, también el hecho de que mi papá estudió hasta el cuarto semestre de físicomatemáticas creo que influyó, pero al último me decidí por la biología porque siento que abarca más.

Flor

Siempre fue lo que me gustó, no sabía que quería ser bióloga pero siempre supe que quería trabajar en algo de la naturaleza. Yo veía los documentales y era así como -ay 
que bonitos yo quiero trabajar como esa persona- pero nunca me había fijado que eran biólogos, ya hasta más grande supe que eran biólogos, no sabía si estudiar desarrollo sustentable de zonas costeras o física o ecología o algo así, pero finalmente los elementos que me interesan de ahí los engloba la biología, entonces me decidí por biología.

Violeta

Entre las estudiantes de Psicología no existe ese consenso respecto al futuro profesional que avizoraron en su infancia ni tampoco es posible apreciar que sus aspiraciones profesionales estén asociadas a una vocación científica, tal vez porque la ciencia psicológica es entendida más como una herramienta útil en la solución de problemas que como un campo de construcción de conocimiento científico. Dos de ellas, Delia y Silvia, manifiestan haber tenido la expectativa de estudiar una carrera universitaria desde niñas pero la psicología no figuraba en su horizonte; mientras que Lila no recuerda haber concebido ninguna expectativa profesional a esa edad y Ruth aspiraba a ser bombero. Será con su ingreso a los estudios medio y medio superior cuando todas desarrollan el proyecto de estudiar una carrera universitaria en psicología, cuya perspectiva clínica es la que más les interesa. Estos son sus relatos:

De niña quería ser dentista, creo que fue por impulso de mis papás que siempre me regalaban juguetitos de doctora o de dentista... y todavía en la prepa seguía con la idea de estudiar odontología (...) pero luego empecé a entrar en conflictos existenciales porque mi hermana estudió odontología, como siempre hubo esa comparación entre mi hermana y yo a ver quién era la mejor, entonces decidí hacer algo diferente. Tuve un profesor de psicología que me gustaban mucho sus clases y que me gustaron los temas que daba de psicopatología y esas cosas, así que decidí estudiar psicología.

Delia

Cuando era niña no me acuerdo qué quería estudiar, creo que no pensaba estudiar nada. De hecho mi mamá era de la idea de que estudiara una carrera corta porque como que todavía tiene esos estereotipos de que la mujer tiene que estar cuidando a sus hijos y me decía: 'al rato te vas a querer casar, entonces para que pierdes el tiempo estudiando, mejor estudias una carrera corta y después trabajas'. Fue hasta 
que entré al $\mathrm{CCH}$ cuando pensé en estudiar Historia o Antropología, pero al final me gustó más psicología, sentí que es una carrera que abarca el estudio de la sociedad a partir de determinados momentos históricos, así que incluye lo histórico, lo antropológico y también lo personal.

Lila

Yo siempre le copiaba a mi hermana, entonces lo que ella decía, yo lo decía, y entonces ella decía: 'yo quiero ser enfermera' y yo quería ser enfermera, 'yo quiero ser maestra', y yo quería ser maestra, y eso fue siempre desde chiquita. Pero lo que más se me quedó era ser maestra (...). Siempre fui buena en las matemáticas, pero nunca pensé en estudiar una carrera de esa área... Fue cuando entré a la secundaria que nos hablaron de la psicología y de que si tienes problemas puedes recurrir a una psicóloga y contarle [lo que te pasa] y ella te va a ayudar, luego creo que vi un programa raro en donde los psicólogos atendían a personas que habían violado o algo así y dije ¡no manches! entonces los psicólogos pueden hacer eso, o sea, ayudan a la gente y dije ¡wowww yo quiero hacer eso!

Silvia

De niña quería ser bombero... sí de hecho me gustaba ver cómo apagaban el fuego y yo quería hacerlo, quería así como ayudar a la gente y correr cuando me piden ayuda (...) En la preparatoria quería estudiar muchas cosas: quería ser físico-matemática, también quería ser bióloga, quería estudiar diseño gráfico o ingeniería en sistemas, pero tuve una maestra de psicología que era muy buena, ella nos decía todo lo que la psicología podía hacer, que se podía ayudar a mucha gente; de hecho ella fue la que me impulsó a estudiar psicología.

Ruth

Como ha mostrado consistentemente la investigación sociológica y psicológica, las aspiraciones educativas de las mujeres están asociadas a los conceptos de feminidad propios de su grupo social, que a su vez están mediados por su clase y etnicidad ${ }^{12}$. En el caso de las estudiantes entrevistadas, es evidente la influencia que tuvo su familia y su

\footnotetext{
12 Dice Bourdieu (2002, p. 106), existen tantas maneras de vivir la feminidad como clases y fracciones de clase existen.
} 
origen social en estas aspiraciones, pero también parece haber incidido una percepción social de la ciencia donde ciertas áreas les resultan más compatibles con su identidad femenina. Es de notar que en ambas carreras encontramos estudiantes que señalaron haber tenido un buen desempeño en matemáticas a lo largo de su trayectoria escolar e incluso mencionaron que pensaron en estudiar física o matemáticas, pero finalmente no lo hicieron. En esta decisión parece haber jugado un papel importante la búsqueda de una carrera que fuera compatible con su manera de interpretar el mundo, con su identidad femenina y con sus expectativas de ejercicio profesional, y tal vez no veían en las matemáticas o la física la posibilidad de hacerlo.

Sí bien los estereotipos de género tienen una importante influencia en la elección de carrera, en este caso se puede apreciar que sus aspiraciones profesionales responden probablemente a la búsqueda de una profesión cuyo ethos científico correspondiera a los principios de justicia y responsabilidad moral que desarrollaron desde niñas, no porque fueran mujeres sino porque fueron socializadas de una manera donde el cuidado por el otro/a formó parte de su núcleo central de valores ${ }^{13}$. Mediante los juegos, las relaciones sociales y la imagen que fueron gestando de sí mismas, desarrollaron la noción de que la ciencia sirve para solucionar problemas y evitar el sufrimiento. Si vemos con atención las respuestas de las estudiantes de ambas carreras, podemos notar que sus argumentos para elegir carrera giran en torno a la idea de protección, apoyo y cuidado; ya sea de la naturaleza, los animales o las personas. Desde la que quiere ser bombero hasta la que aspiraba a ser psicóloga, veterinaria o bióloga, la motivación principal de sus aspiraciones en la infancia se sustentaba en la idea de ayudar, apoyar, cuidar o proteger, ideas que se mantuvieron con diferentes matices hasta el bachillerato cuando finalmente eligen la carrera que ahora estudian. Al parecer en ello interviene una identidad femenina que se ha construido en torno a una ética del cuidado que las lleva a buscar profesiones donde puedan poner en práctica un ethos científico que responda a esas inquietudes.

Todo ello incide en sus elecciones profesionales, pero también en su postura respecto a dedicarse o no a la carrera científica, pues mientras algunas piensan que la forma de

\footnotetext{
${ }^{13}$ Carol Gilligan (1985) destaca el importante papel que tiene el juego en el desarrollo del juicio moral de niñas y niños, pues ello les permite el aprendizaje de las reglas, de las nociones de justicia y de responsabilidad moral. Este juicio moral es resultado de una socialización de género que inicia desde edades muy temprana donde el juego materializa los principios morales del bien y la justicia de una sociedad. Por tanto, el desarrollo del juicio moral en los niños es distinto al de las niñas, pues mientras los primeros se socializan en juegos basados en el cumplimiento de las reglas, las niñas se socializan con juegos que privilegian las relaciones por encima de las reglas. Ella llamó a la primera ética de la justicia, y a la segunda, ética del cuidado.
} 
alcanzar estos objetivos se encuentra en la investigación científica, para otras la vía es la práctica profesional. En esta decisión interviene también el capital cultural con que cuente cada una, pues ello les permitirá ampliar o reducir el horizonte de sus perspectivas profesionales.

\subsection{Sus perspectivas hacia la investigación científica}

Si bien carreras como biología tienen como eje la investigación científica, no todas las chicas que estudian esta carrera optan por dedicarse a esta actividad. De las cuatro estudiantes de Biología, tres de ellas aspiran a dedicarse a la investigación científica y afirman que la investigación es una actividad divertida, que las hace felices. En cambio Magda, quien es la única estudiante de la carrera de Biología que rechaza la idea de dedicarse a la actividad científica, considera que la investigación no es una actividad que le interese, pero manifiesta su interés por combinar la ciencia con el arte. En la tabla 2 se pueden apreciar las respuestas de las entrevistadas:

Tabla 2. Estudiantes de Biología ¿Te piensas dedicar a la investigación?

\begin{tabular}{c|l}
\hline Magda & $\begin{array}{l}\text { No (risas) Porque, mi rollo es como combinar la ciencia con algunas actividades } \\
\text { artísticas, por ejemplo con la fotografía o literatura, tal vez mi rollo va por ahí, pero } \\
\text { como científica, no. }\end{array}$ \\
\hline Raquel & $\begin{array}{l}\text { Sí, en la biología me gusta esa parte de la práctica, la teoría no me gusta mucho, me } \\
\text { encanta estar en campo y eso es lo que yo quiero, trabajar en campo o en } \\
\text { laboratorio, eso me hace muy feliz, entonces dedicarme a la investigación en eso sí. }\end{array}$ \\
\hline Flor & $\begin{array}{l}\text { Como bióloga siempre estás investigando, pero dedicarte de lleno a eso como los } \\
\text { doctores, sí me gustaría, pero también tengo en mente desarrollar alguna empresa o } \\
\text { dirigir proyectos de ecología en comunidades, pero siempre con fundamento } \\
\text { científico. }\end{array}$ \\
\hline Violeta & $\begin{array}{l}\text { Sí, si me gustaría dedicarme a la investigación porque aún quedan muchas cosas } \\
\text { por aprender, por descubrir, además de que es muy interesante, es muy divertido } \\
\text { hacer investigación. }\end{array}$ \\
\hline
\end{tabular}

Fuente: Elaboración propia (2017) con la información proporcionada por las estudiantes entrevistadas

A su vez, las estudiantes de psicología tienen serias dudas respecto a considerar la investigación científica como su proyecto de futuro, tres de ellas consideran más bien tomar otras vías y únicamente Silvia parece estar convencida de que la carrera científica le ofrece un panorama alentador y manifiesta su intención de dedicarse a la investigación. En la tabla 
3 se puede apreciar las respuestas de las estudiantes de psicología respecto a sus perspectivas para dedicarse a la investigación:

Tabla 3. Estudiantes de Psicología ¿Te piensas dedicar a la investigación?

\begin{tabular}{c|l}
\hline Delia & $\begin{array}{l}\text { Mmmm no lo sé, creo que tengo otros planes, no he pensado en dedicarme a } \\
\text { investigar... tal vez en un futuro, pero no sé. }\end{array}$ \\
\hline Lila & $\begin{array}{l}\text { Tengo muchas dudas, no tengo claro a qué me voy a dedicar, pienso que me } \\
\text { gustaría hacer una maestría, tal vez algo relacionado a la psicología social pero } \\
\text { todavía no me he informado. }\end{array}$ \\
\hline Silvia & $\begin{array}{l}\text { Pues... mmm...sí me gustaría mucho, porque la investigación es algo muy noble, si } \\
\text { se lleva bien todos salimos beneficiado de ello; el conocimiento, el aprendizaje es } \\
\text { importantísimo... sí me gustaría. }\end{array}$ \\
\hline Ruth & $\begin{array}{l}\text { Lo he pensado, pero aún estoy con dudas porque no sé bien lo que quiero, entonces } \\
\text { tengo que pensarlo muy bien (...) Yo siento que me faltan algunas habilidades o } \\
\text { capacidades para poder desarrollarme como científica, para llegar a desarrollarme } \\
\text { como investigadora en el área de psicología, no sé siento que me falta mucho. }\end{array}$ \\
\hline
\end{tabular}

Fuente: Elaboración propia (2017) con la información proporcionada por las estudiantes entrevistadas

Una primera mirada a las experiencias narradas por las ocho estudiantes entrevistadas, permite apreciar una continuidad entre su educación científica, su elección de carrera y su interés por la investigación. Quienes accedieron a una educación científica en la infancia, eligieron una carrera con un perfil notoriamente científico como Biología y afirman su intención de dedicarse a la investigación como proyecto de vida. Mientras quienes tuvieron una escasa educación científica en la infancia, eligieron una carrera como Psicología a la que se le reconoce poco su dimensión científica y manifiestan un reducido interés por dedicarse a la investigación. Sin embargo, lejos de plantearnos explicaciones lineales tendremos que revisar con mayor detenimiento cómo operaron los ordenamientos de género a lo largo de su trayectoria escolar.

Las estudiantes de biología que pretenden dedicarse a la investigación contaron con una familia que promovió una socialización de género no sexista donde pudieron construir identidades femeninas que facilitaban su acercamiento a la ciencia y que le dio especial importancia a su educación científica; además, cursaron su educación primaria en escuelas privadas, donde algunas utilizaban sistemas pedagógicos no tradicionales en la enseñanza de la ciencia que despertaron su interés y pasión por la ciencia; y finalmente, encontraron en la educación media y superior los espacios educativos e identitarios que les permitieron consolidar su vocación científica y encontrar en la investigación su proyecto de futuro. Las estudiantes de psicología no contaron con estas condiciones. Ellas refieren haber recibido una socialización de género en la familia donde se promovían roles femeninos más tradicionales, en contextos que no facilitaron su educación científica y con condiciones 
económicas que limitaban sus oportunidades de acercarse a la ciencia. Su formación escolar en la primaria trascurrió bajo modelos pedagógicos acartonados, con programas escolares desvinculados de la ciencia y sin propuestas concretas para despertar su interés por la actividad científica. Finalmente, en su educación media y superior conocieron primordialmente la dimensión profesional de la psicología, más que su dimensión científica y ahora presentan serias dudas respecto a la posibilidad de dedicarse a la investigación porque no alcanzan a vislumbran las posibilidades que ofrece la carrera científica en esta disciplina y desconfían de sus habilidades para la investigación, procesos todos que guardan cierta relación con las identidades femeninas y los desafíos que deben enfrentar en la escuela por su condición de género.

\subsection{La construcción de identidades femeninas y los desafíos de su condición de género en la escuela}

Más allá de las diferentes condiciones que vivieron cada una, las estudiantes de ambas carreras enfrentan desafíos por su condición de género que inciden también en su elección de carrera y su interés por la investigación. Por una parte, todas deben lidiar con una formación académica donde las mujeres son las grandes ausentes ${ }^{14}$, de manera que cuentan con pocos modelos femeninos con los cuales identificarse y constantemente se ven obligadas a redefinirse en términos de un otro masculino donde sus atributos y capacidades son siempre insuficientes. También deben lidiar con un ambiente escolar que las excluye, invisibiliza y discrimina, además de vivir cotidianamente prácticas de sexismo, acoso y devaluación de sus habilidades científicas por parte de sus profesores, de manera que cuando deben elegir áreas disciplinarias ponen en acción diversos mecanismos de autoselección que las llevan a descartar ciertas áreas pese a tener un historial de éxito escolar en esas materias. Sobre ello da constancia el testimonio de Silvia, quien tuvo un desempeño brillante en matemáticas a lo largo de toda su trayectoria escolar y podría haber elegido cualquier carrera del área físico-matemáticas, sin embargo optó por estudiar psicología, una elección que pudo ser el resultado de las experiencias de discriminación y

\footnotetext{
${ }^{14}$ Un estudio donde participaron estudiantes de estas carreras en esta misma Facultad de la UNAM, mostró que el estudiantado recibe una formación profesional androcéntrica donde las mujeres son las grandes ausentes, por tanto, desconocen los nombres y aportes de las mujeres a estas disciplinas. Ante la solicitud de mencionar a tres pioneros o pioneras de cada carrera, apenas el $12 \%$ de las personas mencionadas por el estudiantado de Biología fueron mujeres, mientras que entre el estudiantado de psicología solo el $9.8 \%$ de las y los pioneras/os de la psicología mencionados por el estudiantado fueron mujeres (Guevara y García, 2016). Esta formación profesional que elimina los aportes de las mujeres de la historia de la ciencia no es exclusiva de México, García Dauder, (2005) pudo mostrar que esta ausencia forma parte de la historia de la ciencia en muy diversos países.
} 
sexismo que vivió en su educación matemática y que la llevaron excluir esa área de sus elecciones profesionales. Es de notar que cursar una carrera considerada "femenina" y en una universidad prestigiosa como la UNAM, no las salva de vivir este tipo de experiencias. Este es su relato:

En la prepa tenía un maestro de matemáticas que era machista a más no poder, sí literal, nos ponía en el pizarrón un montón de ejercicios y si pasaba un chico y no sabía, él le empezaba a dictar la respuesta y luego le decía: 'muy bien compañero siéntate', y pasaba una chica y nos quedábamos así temblando, y nos decía: 'señorita eso ya lo tienes que saber desde cuándo, si no sabes entonces no puedes estar aquí, salte una semana hasta que lo sepas hacer y regresas'. Luego, ya aquí en la universidad tenía un maestro de estadística $\mathrm{mmm}$... a nosotras como que nos trataba de 'ay pobrecitas no sabes', pero también nos molestaba y nos ofendía o nos hacía bromas [sexistas] muy pesadas.

Silvia

Los obstáculos que enfrentan las estudiantes por su condición de género no siempre provienen de prácticas abiertas de discriminación o devaluación de sus capacidades, estos obstáculos a veces se encuentran en la noción de ciencia que se les transmite, en sus modelos epistemológicos y su forma de enseñarla. Por ello, es posible que aún estudiantes que eligieron una carrera como Biología que las podría llevar directamente al ámbito de la investigación científica, pueden desistir de esa idea cuando la ciencia a la que acceden no logra despertar en ellas esa pasión por el conocimiento científico ni encuentran en su disciplina una perspectiva que responda a sus necesidades e intereses epistémicos. Pese a que desde sus inicios como disciplina científica la Biología ha estado conformada en su mayoría por mujeres ${ }^{15}$, los planes y programas de estudio que se imparten en las universidades se ciñen a un modelo androcentrista de la ciencia que se expresa desde el lenguaje científico hasta los modelos epistémicos utilizados. Una ciencia donde los criterios de verdad y objetividad se oponen a rasgos considerados femeninos como la subjetividad, la

\footnotetext{
${ }^{15}$ Antes de que se institucionalizara en las universidades la biología como una disciplina científica, ésta era una rama de conocimiento propia de las mujeres, al grado que en 1887 Adams escribió un artículo publicado en Science titulado: "Is Botany a Suitable Study for Young Men?" (Slack, 1987). Una vez que se constituyó como una disciplina científica, las mujeres siguieron siendo mayoría en la matrícula estudiantil pero la biología se instituyó desde la mirada masculina, con los sesgos y exclusiones que ello supuso. Hasta la fecha, esta ha sido esta perspectiva la que ha nutrido los planes y programas de estudio de esta carrera en las universidades donde se imparte la carrera de biología.
} 
afectividad y lo privado; y donde los intereses, necesidades y formas de construcción del conocimiento de las mujeres están excluidos o devaluados, por tanto, es frecuente que algunas estudiantes encuentren dificultades para apropiarse de esos modelos de conocimiento. Tal parece ser el caso de Magda, quien muestra su desilusión por haber estudiado una carrera como Biología que le gusta pero le ofrece un panorama estrecho de la ciencia y que no le permite pensar en la investigación científica como su proyecto de futuro. Estas son sus palabras:

Yo ya no quería seguir con la carrera, porque siempre me han llamado la atención otras cosas... a veces siento que fue una toma de decisión muy apresurada, porque en la prepa no sabía qué estudiar y creo que me aceleré mucho con decir biología, y sí me gusta, pero me gustan otras cosas, o cómo decirlo... me gustaría poder hacerlo desde otra perspectiva, por ejemplo, poder vincular la biología con el arte o poder hacer ciencia pero de otra manera...no sé cómo.

Magda

Se trata de desafíos que inician desde la infancia, pero que se agudizan durante la formación universitaria cuando deben empezar a articular dos mundos que se han construido como incompatibles: el mundo de la ciencia y el mundo de las mujeres. Lo que además ocurre justo en un momento de redefinición de su identidad femenina que se ve interpelada por una doble vía: desde la educación científica que le permite explorar nuevos territorios de conocimiento a la vez que le devuelve una imagen valorada de sí misma; y desde un mundo científico que las excluye e invisibiliza mediante sus teorías, conceptos y epistemologías. Todo ello las obliga redefinirse a contrapelo de los modelos femeninos tradicionales, pero también a contrapelo de una ciencia androcentrista donde frecuentemente no se reconocen; su reto es construir una vía que les permita conciliar ambos mundos.

En los relatos de quienes recibieron educación científica en la infancia, es posible observar que ello les permitió descubrir un panorama deslumbrante que las apasiona y motiva para adentrarse más en el mundo del conocimiento. Pero conforme van avanzando en su trayectoria escolar, esta pasión se va confrontando con una realidad que tiende a alejarlas de esos intereses. Será hasta la universidad cuando encuentren un contexto que les permite volver a activar su pasión por el conocimiento y que logren desarrollar los recursos personales e intelectuales para resistir las adversidades de un mundo donde ellas son tratadas como intrusas. Entonces, empieza a ser más evidente la falta de articulación 
entre su identidad femenina y el mundo prestigioso de la ciencia, porque aún en carreras consideradas "femeninas", la ciencia es un territorio masculino.

Para resolver este dilema, algunas tratan de mimetizarse con sus cohortes masculinos y defender a ultranza la idea de que son "iguales" a ellos, porque situarse como mujeres las coloca en los espacios devaluados del orden de género; mientras que otras recurren a lo que Rivière (2007, p. 219) llegó a llamar "la máscara de la feminidad" y que consiste en desarrollar conductas y apariencias que llevan a "exagerar" su feminidad para evitar las represalias de los varones y la angustia de incorporarse a espacios donde no son bienvenidas. Cada una resuelve el desafío a su manera: las que tienen mejores condiciones logran, no sin dificultades, articular esos dos mundos de la ciencia y sus identidades femeninas y salir adelante; pero las que tienen las condiciones personales y sociales más adversas, no lo consiguen. Como señala Graña (2006, p. 67), en lugar de preguntarnos por qué las mujeres no se interesan en la ciencia, debiéramos preguntarnos cómo trata la ciencia a las mujeres para que ellas no se interesen por la ciencia.

Por ello es necesario prestar mayor atención al papel que juega la escuela en la construcción de identidades femeninas, especialmente en la infancia. Como sostienen diversas autoras (Carrera, Suibirats y Tomé, 2014; Moreno, 1993; Moreno, 2000), la escuela tiene una doble función: la formación intelectual y la formación social de los individuos, y por tanto, se encarga también de la transmisión de un orden de género que es al mismo tiempo sexista y androcentrista. Esta transmisión se ejerce a través de un currículo formal y un currículo oculto que se transmite a niñas y niños desde las edades más tempranas y se expresa en: la utilización cotidiana de un lenguaje sexista que excluye e inferioriza a las niñas; mediante libros de texto donde las mujeres son las grandes ausentes; una visión de la historia donde los personajes son todos masculinos; una ciencia donde los protagonistas, creadores e inventores son varones; y un mundo donde todo lo femenino es considerado menos valioso que lo masculino.

Recientemente, Gabriela Ramos directora de gabinete de la OCDE en México para América Latina dijo, en la presentación del programa NIÑASTEM PUEDEN, que de acuerdo con mediciones del organismo internacional, las niñas tienen menos confianza en sí mismas aunque tengan buen desempeño en matemáticas, y señaló: "lo que indica que el entorno social, cultural y familiar transmite menos el nivel de ambición para las niñas" (Inzunza, 2017, párr. 3). Es decir, se sigue pensando que el problema está en las niñas y su falta de ambición, no en las condiciones estructurales y simbólicas del orden de género que limita 
sus oportunidades y les ofrece una imagen devaluada de sí mismas. La discriminación sexista, dice Subirats (1988, p. 29), no afecta la capacidad de éxito escolar de las niñas, pero sí la construcción de su personalidad y la seguridad en sí mismas, porque en la escuela se esculpe la personalidad humana y se transmite la jerarquía de valores asociados al género. Si las mujeres no desarrollan seguridad en sí mismas, ello obedece en gran medida a la forma distorsionada en que la sociedad ha construido la imagen femenina mediante diversos mecanismos, uno de ellos se encuentra en el universo simbólico del lenguaje. Dice Femenías:

Cuando históricamente las apelaciones a las mujeres han sido del tipo Eh, tu, fregona / tonta / diosa / frívola / inconsciente / vulnerable / bruja / incapaz / quejosa / loca / puta... es de suponer que (...) las mujeres se reconozcan y confirmen su identidad según esas descripciones. Además, esas designaciones, le dan un lugar en los discursos que es jerárquicamente inferior y descalificante. Como incluso no son los únicos machacados hasta el hartazgo en este sentido (la ciencia y la religión hacen también su parte), es oportuno concluir que aquí también se ha producido una operación normativizadora, reguladora y generadora de identidad. A esa forma de violencia simbólica la vamos a denominar poder heterodesignativo del lenguaje y constituye una forma violenta de construcción de identidad. (2006, párr. 12)

De ahí la importancia de desarrollar programas de enseñanza de la ciencia que no sólo proporcionen información científica, sino que se propongan desmontar los ordenamientos de género presentes en la escuela, en la enseñanza de la ciencia, y en la ciencia misma.

\section{Conclusiones}

Las experiencias narradas por las estudiantes universitarias que participaron en este estudio nos ofreció un panorama sobre la forma en que operaron los ordenamientos de género en la educación científica recibida durante su infancia pero, como toda la investigación cualitativa, no pretende generalizar sus resultados a otros sectores o contextos, sino profundizar en la comprensión del fenómeno de estudio para ofrecernos indicadores de cómo funciona estos procesos. Como diría Haraway (1991), el conocimiento adquirido mediante esta modalidad metodológica, es parcial, local y situado desde la realidad y los significados de quienes participaron en el estudio y de su contexto específico de vida, pero ello lejos de invalidarlo, le confiere una enorme riqueza para comprender la articulación de 
los complejos factores que intervienen en la construcción de vocaciones científicas y elecciones profesionales en las niñas y mujeres de nuestra región.

A su vez, estos estudios cualitativos nos permiten identificar cómo se articulan factores como la clase social con el orden de género, pues como vimos en las páginas anteriores, las estudiantes entrevistadas no constituyen un grupo homogéneo, algunas pertenecen a sectores medios mientras que otras pertenecen a sectores populares, una situación que incide en el tipo de escuela a la que pueden asistir y el tipo de educación científica que pueden recibir. En México, las escuelas particulares suelen tener mejores condiciones materiales y pedagógicas para ofrecer una educación científica de calidad a las niñas y niños, pues cuentan con las condiciones económicas para dotar de equipo, materiales y personal calificado a sus escuelas (dado su carácter de empresa privada), y de propuestas educativas para atender la demanda de ciertos sectores medios ilustrados cuyos progenitores pueden tener especial interés en proporcionar educación científica a sus hijas. Por el contrario, el presupuesto que el gobierno federal destina a las escuelas públicas es muy reducido y sus espacios educativos carecen de infraestructura, programas, materiales y personal calificado para atender la educación científica de las niñas y niños que asisten a sus aulas, y como ha señalado Flores-Camacho (2012, p. 5), estas deficiencias se agudizan en determinados sectores según la región, clase social, etnia y sexo de la población.

Así, pese al reducido número de las personas participantes en el estudio, estas entrevistas ofrecen valiosas pistas para reconocer que la educación científica que se imparte a las niñas es vital en la construcción de vocaciones científicas y en las aspiraciones que ellas desarrollan para optar por una carrera científica; además, este tipo de educación constituye una valiosa herramienta para superar los retos que les impone los ordenamientos de género presentes en la sociedad, la escuela y la familia. Su acceso a la educación científica les proporciona recursos simbólicos e intelectuales para inclinarse por carreras científicas y para considerar la investigación como su proyecto de futuro, más aún, les permite construir identidades que rompen con los modelos femeninos tradicionales y atisbar otros horizontes al pensarse como sujetos epistémicos. Por eso mismo, cuando la sociedad, la familia o la escuela trunca sus oportunidades de educación científica, restringe su horizonte de vida como mujeres, pues la educación científica es mucho más que el aprendizaje de ciertas asignaturas, es el ingreso a un mundo de posibilidades que contribuye poderosamente al proceso de construcción de nuevas identidades femeninas, y al desarrollo de potencialidades que les devuelven a las niñas y jóvenes una imagen valorada de sí 
mismas y de un mundo donde ellas pueden contribuir a resolver los grandes problemas que afectan su entorno.

Con todo, no basta con extender el acceso al conocimiento científico a mayor cantidad de niñas, pues el campo de la ciencia también está teñido por los ordenamientos de género que excluyen las dimensiones femeninas de la ciencia e imponen a las mujeres mayores obstáculos para incorporarse a este terreno. Ambas condiciones inciden en las elecciones profesionales y vocaciones científicas de las estudiantes, porque estudiar una carrera científica o dedicarse al campo de la investigación, les exige una enorme inversión de energía psíquica para superar las distintas barreras que enfrentan. Desde la teoría feminista se han elaborado importantes propuestas para transformar esta situación. Por una parte, se propone visibilizar y reconocer los aportes de las mujeres a la ciencia para que las nuevas generaciones de estudiantes e investigadoras tengan un espejo virtuoso de reconocimiento de sí mismas. Por otra parte, consideran que es indispensable transformar la ciencia misma, sus teorías, conceptos, metodologías y valores epistémicos, a fin de que se puedan incluir todas aquellas dimensiones femeninas que han sido excluidas de la ciencia. Al mismo tiempo, proponen nuevos modelos pedagógicos que podrían aplicarse en los programas de educación científica para que las niñas y jóvenes puedan adquirir las herramientas intelectuales, políticas y personales que les permitan acercarse a la ciencia desde otras miradas, y además, obtener los recursos políticos e intelectuales para cuestionar ese orden (Blazquez, 2010; Bustos, 2005; García Dauder, 2005; González y Pérez, 2002).

Especialmente importantes son las pedagogías feministas que, apoyadas en los enfoques epistemológicos sobre conocimiento situado (Harding, 1996) y en la pedagogía crítica de Paulo Freire $(1970)^{16}$, subrayan la importancia de reconocer otras epistemes que posibilitan plantear nuevas formas de relación entre conocimiento y poder, otras teorías del conocimiento desde las cuales se trastoquen las relaciones de género en los procesos educativos y se reconozca a las mujeres como sujetos epistémicos. Se trata de una perspectiva que se alimenta del feminismo de-colonial (Korol, 2007; Maffía, 2012; Pérez

\footnotetext{
16 Las pedagogías críticas de América Latina surgidas de la filosofía de la liberación y de los aportes de Paulo Freire, destacan el poder que significa para los grupos oprimidos su acceso a la educación. Freire introdujo un nuevo marco de análisis que colocaba en el centro de la reflexión las relaciones asimétricas de poder que se viven en los procesos educativos mediante recursos pedagógicos que despojan de voz al educando y le imponen saberes y visiones del mundo que contribuyen a sus condiciones de opresión. Esta pedagogía, propone estrategias de resistencia de los sectores oprimidos de la sociedad que rebasan el campo educativo y se vinculan con procesos de democratización, emancipación y ejercicio de la ciudadanía en todos los espacios de la vida (Cabaluz, 2015; Dussel, Mendieta y Bohórquez, 2008).
} 
Bustos, 2010) y que busca hacer visibles saberes descalificados por la ciencia hegemónica para establecer relaciones más horizontales entre todos los sujetos del proceso educativo. Tales propuestas no sólo pueden contribuir a remontar los obstáculos que enfrentan las niñas y jóvenes para incorporarse al campo de la ciencia, sino también podrían beneficiar a niños y varones que no encajan en los modelos de masculinidad hegemónica y que requieren, como ellas, de otros lenguajes y recursos pedagógicos para acercarse a la ciencia. Esto permitiría abrir nuevos horizontes en la educación científica de niñas y niños en un país como México, y una región como América Latina, que necesitan urgentemente incorporar a sus comunidades científicas el talento y la conciencia crítica de quienes han sido excluidas de ellas.

\section{Agradecimientos}

Esta investigación forma parte del proyecto PAPIIT IN302316 La educación científica de jóvenes universitarias. Trayectoria escolar y vocaciones científicas financiado por la Dirección General del Personal Académico de la Universidad Nacional Autónoma de México, a quien se agradece su apoyo.

\section{Referencias}

Aguiar, Martha Elena, Gutiérrez, Humberto, Lara, Antonio y Villalpando, José Francisco (2011). El rendimiento académico de las mujeres en matemáticas: análisis bibliográfico y un estudio de caso en educación superior en México. Actualidades Investigativas en Educación, 11(2), 1-24. Doi 10.15517/aie.v11i2.10198

Álvarez-Lires, Francisco, Arias, Azucena, Serrallé, Francisco y Varela, Mercedes. (2014). Elección de estudios de ingeniería: Influencia de la educación científica y de los estereotipos de género en la autoestima de las alumnas. Revista de Investigación en Educación, 12(1), 54-72.

Blazquez, Norma. (2010). Epistemología feminista: temas centrales. En Norma Blazquez, Fátima Flores y Maribel Ríos (Comps.), Investigación Feminista: Epistemología y Representaciones Sociales (pp. 21-38). México: CEIICH-CRIM, Facultad de Psicología, UNAM.

Bonder, Gloria (2014). El enfoque de género en el ADN de la educación científicotecnológica: propuestas para la transformación educativa en y para la Sociedad del Conocimiento. New York: United Nations. Recuperado de http://flacso.org.ar/publicaciones/el-enfoque-de-genero-en-el-adn-de-la-educacioncientifico-tecnologica/

Bourdieu, Pierre. (1993). La Miseria del Mundo. México: Fondo de Cultura Económica. 
Bourdieu, Pierre. (2002). La Distinción. Criterio y bases sociales del gusto. México: Taurus.

Bustos, Olga. (2005). Recomposición de la matrícula universitaria a favor de las mujeres. Repercusiones educativas, económicas y sociales. En Rosaura Sierra y Gisela Rodríguez, Feminización de la Matricula de Educación Superior en América Latina y el Caribe (pp. 257-290). México: ITESAL-UDUAL.

Cabaluz Ducasse, Fabián. (2015). Entramando pedagogías críticas latinoamericanas: notas teóricas para potenciar el trabajo político-pedagógico comunitario. Santiago de Chile: Editorial Quimantú.

Carrera, Anna, Subirats, Marina y Tomé, Amparo. (2014). La Construcción de los géneros en la etapa 0-3: Primeras exploraciones. Recuperado de http://www.bdv.cat/sites/default/files/common/Dones/article coeduaccio la construccio $\underline{\mathrm{n} \text { de los generos en la etapa 0-3.pdf }}$

Castro, Roberto. (1996). En busca del significado: Supuestos, alcances y limitaciones del análisis cualitativo. En Ivonne Szasz y Susana Lerner (Comps.), Para Comprender la Subjetividad. Investigación cualitativa en salud reproductiva y sexualidad (pp. 57-85). México: El Colegio de México.

Céspedes, Catalina y Robles, Claudia. (2016). Niñas y Adolescentes en América Latina y el Caribe. Deudas de igualdad (Serie: Asuntos de Género No. 133). Santiago: Naciones Unidas-CEPAL-UNICEF.

Clair, Renée. (1995). The Scientific Education of Girls. Education beyond reproach? Great Britain: UNESCO.

Cobo, Rosa. (1995). Género. En Celia Amorós (Dir), 10 Palabras Clave sobre Mujer (pp. 5584). España: Editorial Verbo Divino.

Duru-Bellat, Marie. (1995). Orientation and Success in the Scientific Streams. En Renée Clair (Ed.), The Scientific Education of Girls. Education Beyond Reproach? (pp. 65-90). Great Britain: UNESCO.

Dussel, Enrique, Mendieta, Eduardo y Bohórquez, Carmen (Eds.). (2008). El Pensamiento Filosófico Latinoamericano, Del Caribe y Latino. México: Siglo XXI Editores.

Instituto Nacional de Estadística y Geografía (INEGI). (2013). Encuesta sobre la percepción pública de la ciencia y la tecnología en México. México: INEGI.

Espinosa, Claudia. (2009). Estudio de las interacciones en el aula desde una perspectiva de género. Ponencia presentada en el I Coloquio Internacional de la Red de Estudios de género del Pacífico Mexicano, realizado en Nuevo Vallarta, Nayarit, entre el 22 y el 24 de abril.

Femenías, María Luisa. (2006). Construcción y deconstrucción de identidades: algunas observaciones entorno a la violencia. Labrys, études féministes. Recuperado de https://www.labrys.net.br/labrys10/livre/maria\%20luisa.htm 
Flores-Camacho, Fernando (Coord.). (2012). La enseñanza de la ciencia en la educación básica en México. México: Instituto Nacional para la Evaluación de la Educación.

Freire, Paulo. (1970). Pedagogía del Oprimido. México: Siglo XXI Editores.

García Dauder Silvia. (2005). Psicología y Feminismo. Historia olvidada de mujeres pioneras en Psicología. Madrid: Narcea Ediciones.

García Ramírez, Carmen Teresa. (2014). Permanencia de estereotipos de género en la escuela inicial EDUCERE, 18(61), 439-447. Recuperado de http://www.saber.ula.ve/bitstream/123456789/39758/1/art5.pdf

González, Marta y Pérez, Eulalia. (2002). Ciencia, tecnología y género. Revista Iberoamericana de Ciencia, Tecnología, Sociedad e Innovación, (2). Recuperado de http://www.oei.es/historico/revistactsi/numero2/varios2.htm

Graña, Francois. (2006). Una revisión de estudios recientes. Igualdad formal y sexismo real en la escuela mixta. Revista de Ciencias Sociales, (23), 63-75.

Guevara, Elsa. (2010). Cuando el Amor se instala en la modernidad. Intimidad, masculinidad y jóvenes en México. México: UNAM, FES-Zaragoza-Centro de Investigaciones Interdisciplinarias en Ciencias y Humanidades.

Guevara, Elsa. (2012). El contexto de la ciencia en México y las perspectivas del estudiantado. En Elsa Guevara (Coord.), El Sueño de Hypatia. Las y los estudiantes de la UNAM ante la carrera científica (pp. 19-43). México: UNAM, FES-Zaragoza-Centro de Investigaciones Interdisciplinarias en Ciencias y Humanidades.

Guevara, Elsa y García, Alba (Coord.). (2016). Académicas que inspiran vocaciones científicas. La mirada de sus estudiantes. México: Universidad Nacional Autónoma de México- Centro de Investigaciones Interdisciplinarias en Ciencias y Humanidades. Recuperado de http://computo.ceiich.unam.mx/webceiich/docs/libro/Academicas\%20que\%20inspiran\% 20WEB.pdf

Guevara, Elsa; Rosado, Ana María; García, Alba y Magaña, Héctor. (2016). Los talleres de ciencia para jóvenes y el orden invisible de género. Revista Mexicana de Orientación Educativa, 13(30), 2-7.

Gilligan, Carol. (1985). La Moral y la Teoría. México: Fondo de Cultura Económica.

Haraway, Donna. (1991). Ciencia, cyborgs y mujeres: la reinvención de la naturaleza. Madrid: Cátedra. Recuperado de http://kolectivoporoto.cl/wp-content/uploads/2015/11/HarawayDonna-ciencia-cyborgs-y-mujeres.pdf

Harding, Sandra. (1996). Ciencia y Feminismo. Madrid: Morata.

Informe ENWISE. (2004). Waste of Talents: turning private struggles into a public issue. European Commission. ENWISE Expert Working group on Women Scientists. 
Recuperado de https://ec.europa.eu/research/swafs/pdf/pub gender equality/enwise$\underline{\text { report en.pdf }}$

Informe ETAN. (2000). Science policies in the European Union: Promoting excellence through mainstreaming gender equality. A Report from the ETAN Expert Working group on Women and Science. Recuperado de http://www.amites.org/sites/default/files/pdf/publicaciones/informe ETAN 2000.pdf

Inzunza, Anayansin. (2017). Promueve NIÑASTEM PUEDEN el gusto por las carreras científicas. La Jornada en la Ciencia. Recuperado de http://ciencias.jornada.com.mx/2017/06/20/promueve-201cninastem-pueden201dgusto-por-las-carreras-cientificas-7277.html

Keller, Evelyn Fox. (1995). Reflections on Gender and Science. New Haven and London: Yale University Press.

Korol, Claudia. (2007). Hacia una Pedagogía Feminista: Géneros y educación popular. Buenos Aires: Editorial El colectivo. Recuperado de http://libros.metabiblioteca.org/handle/001/434

León, Francisco José y Mora, Enrico. (2010). Género y vocación científica. Un estudio de caso basado en mecanismos. Revista Internacional de Sociología, 68(2), 399-428.

Maffía, Diana. (2005). Epistemología feminista: por otra inclusión de lo femenino en la ciencia. En Norma Blazquez y Javier Flores (Eds.), Ciencia, tecnología y género en Iberoamérica (pp. 623-634). México: CEIIH-UNAM.

Maffía, Diana. (febrero, 2012). Alegato desde la periferia. Ponencia presentada en el IX Congreso Iberoamericano de Ciencia Tecnología y Género, Sevilla, España. Recuperado de http://www.oei.es/historico/congresoctg/memoria/mesas.php

Manassero, Ma. Antonia y Vázquez, Ángel. (2003). Los estudios de género y al enseñanza de las ciencias. Revista de Educación, (330), 251-280. Recuperado de http://www.mecd.gob.es/dctm/revista-deeducacion/articulosre330/re3301411213.pdf?documentld=0901e72b81258cd4

Mingo, Araceli. (2006). ¿Quién mordió la manzana? Sexo. Origen Social y Desempeño en la Universidad. México: UNAM, CESU-PUEG-F.C.E.

Moreno, Emilia. (2000). La transmisión de modelos sexistas en la escuela. En Ángel Santos (Coord.), El harén pedagógico. Perspectiva de género en la organización escolar (pp. 11-32). Barcelona: Biblioteca de Aula.

Moreno, Montserrat. (1993). Cómo se enseña a ser niña: Sexismo en la escuela. Barcelona: ICARIA Editorial.

Nuño, Teresa. (2000). Género y ciencia. La educación científica. Revista de Psicodidáctica, (9), 183-214. Recuperado de http://www.ehu.eus/ojs/index.php/psicodidactica/article/viewFile/130/360 
Organización para la Cooperación y el Desarrollo Económicos (OCDE). (2015). Programa para la evaluación internacional de alumnos (PISA). PISA 2015 - Resultados. Recuperado de: https://www.oecd.org/pisa/PISA-2015-Mexico-ESP.pdf

Pérez Bustos, Tania. (2010). Aportes feministas a la educación popular: entradas para repensar pedagógicamente la popularización de la ciencia y la tecnología. Educação e Pesquisa, 36(1), 243-260. Doi 10.1590/S1517-97022010000100004

Riquelme, Angélica y Quintero, Josefina. (2015). Reproducción de identidad virtual de género en la interacción docentes-alumnado. Un estudio de caso. Revista Electrónica Actualidades Investigativas en Educación, 15(2), 1-27. Doi doi.org/10.15517/aie.v15i2.18964

Rivière, Joan. (2007). La femineidad como máscara. Athenea Digital, (11), 219-226. Recuperado de http://atheneadigital.net/issue/view/n11

Rossi, Alice. (1965). Women in Science: ¿Why so few? Science, 148(3674), 1196-1202. Sañudo, Ma. Isabel y Perales, Ruth. (2014). Aprender ciencia para el bien común. Perfiles Educativos, 36(143), 29-38.

Slack, Nancy. (1987). Nineteenth-Century American Women Botanists: Wives, Widows, and Work. En Pnina G., Abir-AM and Dorinda Outram (Eds.), Uneasy Careers and Intimate Lives. Women in Science, 1789-1979 (pp. 77-103). New Brunswick: Rutgers University Press.

Subirats, Marina. (1988). De los dispositivos selectivos en la educación: el caso del sexismo. Revista de la Asociación de Sociología de la Educación, 9(1), 22-36.

Taylor, Steven y Bogdan, Robert. (1987). Introducción a los métodos cualitativos de investigación. Barcelona: Paidós Básica.

Vela, Fortino. (2001). Un acto metodológico básico de la investigación social: la entrevista cualitativa. En Ma. Luisa Tarrés (Coord.), Observar, Escuchar y Comprender sobre la Tradición Cualitativa en la Investigación Social (pp. 63-96). México: Miguel Ángel Porrúa-COLMEX. 